\title{
Analysis of consumer behaviour in a retail drugstore chain in Russia based on the type of consumer loyalty
}

\author{
Galina Galkina*, Elena Gribkova, Tatiana Pak, Olga Bazarkina, Kristina \\ Sudarenko, Maxim Kurashov, Alexey Smirnov \\ Department of Pharmaceutical Management and Economics, Medical Institute, People's Friendship University of Russia, \\ Moscow 11719, Russian Federation
}

*For correspondence: Email: galkina_ga@pfur.ru; Tel: +9 165060894

\begin{abstract}
Purpose: To identify the consumer loyalty types in a retail segment of the Russian pharmaceutical market.

Methods: A sociological study was conducted in pharmaceutical organisations of various forms of ownership, located in different administrative districts of Moscow (Russian Federation). This was done using a questionnaire developed in advance, and based on literature review. The survey involved 480 respondents selected in a simple random sampling.

Results: All questionnaire filled out by the respondents were considered valid. Analysis of the loyalty parameters obtained during the study are as follows: (1) behavioural (repeated purchases), (2) emotional (subjective opinions and experience, sympathy, respect for the brand, etc) and (3) rational (utility assessment) components (4) consumer satisfaction, (5) the desire to buy again, (6) the ability to switch to competitors. They were allocated to four consumer segments. In the course of the study, one consumer segment identified a type of loyalty that had not been previously reviewed by other authors; therefore, a modified classification of the loyalty types was created. Under this classification, constancy, constancy imaginary, inconstancy, and migratory loyalties can be some types of loyalty. The identified socio-demographic characteristics of the respondents influenced the categorization of the loyalty type. Conclusion: A modified classification of loyalty types was created which serves as a parameter for segmentation of the respondents into four groups, with well-readable characteristics and the primary trends in making purchases.
\end{abstract}

Keywords: Consumer loyalty, Consumer behaviour, Migratory loyalty, Consumer segments, Pharmaceutical market

This is an Open Access article that uses a fund-ing model which does not charge readers or their institutions for access and distributed under the terms of the Creative Commons Attribution License (http://creativecommons.org/licenses/by/4.0) and the Budapest Open Access Initiative (http://www.budapestopenaccessinitiative.org/read), which permit unrestricted use, distribution, and reproduction in any medium, provided the original work is properly credited.

Tropical Journal of Pharmaceutical Research is indexed by Science Citation Index (SciSearch), Scopus, International Pharmaceutical Abstract, Chemical Abstracts, Embase, Index Copernicus, EBSCO, African Index Medicus, JournalSeek, Journal Citation Reports/Science Edition, Directory of Open Access Journals (DOAJ), African Journal Online, Bioline International, Open-J-Gate and Pharmacy Abstracts

\section{INTRODUCTION}

For the improvement of the quality of pharmaceutical care, creating a competitive advantage for pharmacies requires not only clear knowledge regarding consumer needs, but also a segmentation of their set, to ascertain their general characteristics and distinctive features and create personalised value propositions for the requests and needs of each. 
As a sign of the segment, we have chosen consumer loyalty; since, ranging from the mid70 s of the last century to the present, it remains a multifaceted value, which includes the main characteristics of consumer behavior [1,2]. On the basis of the generalisation of literature review, loyalty was understood by us as the sum of the following components: Behavioural (frequency of using pharmaceutical assistance services, repeated purchases), emotional and rational (utility evaluation) components, consumer satisfaction, willingness to buy to use the service again, the ability to switch to competitors [3-6].

Under the emotional component of loyalty, we understood the involvement of the consumer at the level of feelings and emotions in terms of the pharmacy; whether the consumer considers himself a regular customer, is he willing to remain so in different situations - such as the temporary absence of the right product - etc.

For improving competition self-efficacy of pharmacies, it was also important to determine whether there is any influence of emotions on consumer' medicines purchases in the retail segment of the pharmaceutical market. Medicines, which dispensed by pharmacies, are essential products to treat the disease, however, it is not always the products that are desired by consumers.

One of the main priorities of the national policy of Russia in the field of health care is the accessibility of pharmacy and the availability of medicine. In Moscow, Russia, there were 2,750 inhabitants per drug store in 2015, and then decreased to 2,220 in 2017 . This shows that the number of pharmacies is increasing, but it can lead to increased competition among pharmacies. This competition in European countries is lower with the average of 3,766 people per pharmacy. In Tanzania, there is the lowest competition with 101,515 people per pharmacy [8].

Regulatory documents governing the opening of pharmacy organizations in Russia do not impose requirements on the distance between pharmacies or on the minimum number of residents who have access to a pharmacy organization [9].

In order to provide consumers with pharmaceutical assistance, meeting their needs and expectations, it is important to regularly monitor the main trends in their behaviour, which determines the purchase of pharmacy goods $[1,7]$.
In this situation, information about consumers, based on which relevant value propositions will be formed, can help improve the quality and service of pharmaceutical care and save the business.

\section{EXPERIMENTAL}

\section{Study design and data collection}

The survey was conducted from September 2014 to May 2015 among pharmaceutical consumers at community pharmacies of various forms of ownership in Moscow. Of the 150 pharmacies that collaborated with Peoples' Friendship University of Russia (RUDN University), 38 were selected due to their launching of loyalty programs for customers, along with the introduction of a customer database. In the community pharmacies participating in the study, a total of 480 customers were interviewed, following which, the pharmacy staff filled their responses in the questionnaires. The sample of respondents were selected based on two criterion: (1) the respondents who made the purchase; (2) the respondents owning a loyalty program card of the pharmacy. Great attention was paid to the quality of responses in the questionnaires, for which the pharmacy employee was personally responsible.

\section{Study tool}

The questionnaire used in the study was developed on the basis of literature review, and consisted of several blocks:

Block 1: (1) identification of the emotional component of loyalty; whether they consider themselves to be regular consumers, are they willing to put up with the potential difficulties that can arise (for instance, the absence of the necessary product), etc.; (2) identification of the behavioural component - the frequency of using pharmaceutical care, making the same purchases in the same pharmacy or in a different one, (3) identification of a rational component the criterion for choosing a pharmacy, the possibility of replacing the drug as well as the likelihood of switching to competitors (are the right products ready to wait and their costs) and (4) satisfaction with the received pharmaceutical care.

The questions in this block were semi-closed, containing a specially developed list of possible, expected options and free space to note the respondents' self-formulation answers.

Block 2: Socially; the demographic 
characteristics of the consumers (gender, age, education, total monthly family income, spending on pharmacy goods).

This block contained closed questions, the respondent chooses from the answers offered to him in the questionnaire.

\section{Ethical approval}

The study followed the principles and guidelines of Declaration of Helsinki [10]. In addition, ethical approval was obtained from the Ethics Committee of Peoples' Friendship University of Russia (no. 1827), Moscow, Russia.

\section{Data analysis}

To identify the socio-demographic and economic characteristics of the consumers who significantly affect the manifestation of the emotional and behavioural components of loyalty, we used the methodology of descriptive statistics by using IBM SPSS software.

\section{RESULTS}

The technology for analysing the research results included the following: (1) studying consumer characteristics; (2) identifying the loyalty components and analysing them, based on a study of existing classifications, and (3) the segmentation of consumers of pharmaceutical care by loyalty type.

\section{Demographics}

A total of 480 questionnaires were completed correctly. The majority of respondents were women $(71 \%)$, aged between 30 and 50 years (54\%), and with higher education (58\%). The frequency of availing pharmaceutical care at pharmacies was 2.3 times, monthly. The average cost for the purchase of the pharmacy products were US $\$ 410$ per year.

There was also a tendency of seeing an increase in the frequency of visit to pharmacy organisations. On the contrary, most of the respondents under the age of 20 visited pharmacies less than one time, monthly. Twenty to forty year-olds visited pharmacies one to two times a month and chose age 40 and older, visited two to four times a month.

\section{Loyalty type}

To determine the type of customer loyalty in the retail segment of the pharmaceutical market, the following were done: (1) the existing classifications of loyalty were analysed, and (2) the six main components of loyalty were identified, and depending on its manifestation, another loyalty type was formed. As a result, the four combined classes of consumer loyalty types were formed (Table 1).

Class I is characterised by the presence of all six components of loyalty, with their positive qualitative characteristics, i.e. emotional affection, regular re-purchases, etc.

This class includes a mixed loyalty type defined by Hofmeyr and Rice $[1,6]$ and a complex loyalty (true) defined by Aaker et al $[1,3]$.

For class II, the primary feature is the negative emotional component - consumers of this loyalty type do not experience emotional attachment to the product/service, while maintaining a positive behavioural component - and regular, repeat purchases for a number of reasons. This class includes transactional loyalty [3], behavioural loyalty [4], behavioural loyalty [6], and comprehensive loyalty (false) [3].

Class III is characterised by a positive emotional component, with a negative behavioural attitude (due to the inability to use the product/service). In this class the following types are combined: emotional loyalty [4], and comprehensive loyalty (latent) [3].

Class IV includes the loyalty types where the behavioural component is not considered. Due to the difference in the qualitative characteristic of the emotional component, two subclasses are distinguished here - IVa, with a positive emotional component, and $\mathrm{IVb}$, with a negative emotional component.

IVa. This subclass includes emotional loyalty [2], perception loyalty [3], and commitment [6].

IVb. This subclass includes evaluative loyalty [4], which is the dominant rational component.

Class I is characterised by the presence of all six components of loyalty, with their positive qualitative characteristics, i.e. emotional affection, regular re-purchases, etc.

This class includes a mixed loyalty type defined by Hofmeyr and Rice $[1,6]$ and a complex loyalty (true) defined by Aaker et al $[1,3]$. For class II, the primary feature is the negative emotional component - consumers of this loyalty type do not experience emotional attachment to the product/service, 
Table 1: Correlation of consumer segments allocated during research and joint classification of the types of loyalty

\begin{tabular}{|c|c|c|c|c|c|c|}
\hline \multirow{3}{*}{ Loyalty type } & \multicolumn{6}{|c|}{ Manifestation of Loyalty Criteria for a Given Type of Loyalty * } \\
\hline & Emotional & $\begin{array}{l}\text { Behavioural } \\
\text { (repeat } \\
\text { purchases) }\end{array}$ & $\begin{array}{c}\text { Rational } \\
\text { (utility } \\
\text { evaluation) }\end{array}$ & $\begin{array}{l}\text { Consumer } \\
\text { satisfaction }\end{array}$ & $\begin{array}{c}\text { Desire to } \\
\text { acquire } \\
\text { again }\end{array}$ & $\begin{array}{c}\text { Ability to } \\
\text { switch to } \\
\text { competitors }\end{array}$ \\
\hline & \multicolumn{6}{|c|}{$I$} \\
\hline Mixed type & Yes & Yes & Yes & Yes & Yes & No \\
\hline $\begin{array}{l}\text { Complex loyalty } \\
\text { (true) }\end{array}$ & Yes & Yes & Yes & Yes & Yes & No \\
\hline $\begin{array}{l}\text { Segment } 1 \\
\text { (26\%) }\end{array}$ & Yes & Yes & Yes & Yes & Yes & No \\
\hline \multicolumn{7}{|c|}{ II } \\
\hline $\begin{array}{l}\text { Transactional } \\
\text { loyalty }\end{array}$ & No & Yes & $-* *$ & $-* *$ & Yes & Yes \\
\hline $\begin{array}{l}\text { Behavioural } \\
\text { loyalty } \\
\text { Behavioural }\end{array}$ & No & Yes & Yes & $-* *$ & Yes & Yes \\
\hline $\begin{array}{l}\text { loyalty (loyalty } \\
\text { without }\end{array}$ & No & Yes & $-* *$ & No & No & Yes \\
\hline $\begin{array}{l}\text { commitment) } \\
\text { Complex loyalty } \\
\text { (false) }\end{array}$ & No & Yes & Yes & No & Yes & Yes \\
\hline \multicolumn{7}{|c|}{ III } \\
\hline $\begin{array}{l}\text { Commitment } \\
\text { without loyalty }\end{array}$ & Yes & No & Yes & Yes & Yes & Yes \\
\hline $\begin{array}{l}\text { Complex loyalty } \\
\text { (latent) }\end{array}$ & Yes & No & Yes & Yes & Yes & Yes \\
\hline $\begin{array}{l}\text { Segment } 2 \\
(25 \%)\end{array}$ & Yes & No & Yes & Yes & Yes & Yes \\
\hline \multicolumn{7}{|c|}{ IVa } \\
\hline Emotional loyalty & Yes & $-* *$ & $-* *$ & $-* *$ & Yes & Yes \\
\hline $\begin{array}{l}\text { Perception } \\
\text { loyalty }\end{array}$ & Yes & $-\star \star$ & Yes/No & Yes/No & Yes & $-\star *$ \\
\hline \multicolumn{7}{|c|}{$I V b$} \\
\hline Commitment & Yes & $-* \star$ & No & Yes & Yes & No \\
\hline $\begin{array}{l}\text { Evaluative } \\
\text { loyalty }\end{array}$ & No & $-\star \star$ & Yes & $-* *$ & Yes & Yes \\
\hline $\begin{array}{l}\text { Segment } 3 \\
(39 \%)\end{array}$ & No & No & Yes & Yes/No & Yes/No & Yes \\
\hline $\begin{array}{l}\text { Segment } 4 \\
(10 \%)\end{array}$ & No & Yes & Yes & Yes & Yes & Yes \\
\hline
\end{tabular}

${ }^{\star \star}$ Not considered; ${ }^{\star} Y e s-$ positive manifestation; No - negative manifestation of the constituent

while maintaining a positive behavioural component - and regular, repeat purchases for a number of reasons. This class includes transactional loyalty [3], behavioural loyalty [4], behavioural loyalty [6], and comprehensive loyalty (false) [3].

Class III is characterised by a positive emotional component, with a negative behavioural attitude (due to the inability to use the product/service). In this class the following types are combined: emotional loyalty [4], and comprehensive loyalty (latent) [3].

Class IV includes the loyalty types where the behavioural component is not considered. Due to the difference in the qualitative characteristic of the emotional component, two subclasses are distinguished here - IVa, with a positive emotional component, and IVb, with a negative emotional component.

IVa. This subclass includes emotional loyalty [2], perception loyalty [3], and commitment [6].

IVb. This subclass includes evaluative loyalty [4], which is the dominant rational component.

Thus, the components of loyalty and their qualitative characteristics, revealed during the research, can serve as a sign of segmentation of the consumers by the type of manifested loyalty.

Based on application of loyalty type, consumers 
were divided into 4 segments (Table 1).

The primary features of the segment were the behavioural component of loyalty, closely related to the economic result of the organisation's activities, and the emotional component of loyalty-influencing development of long-term relationships that become the basis for managing customer relationships.

\section{Segment 1}

A set of qualitative characteristics of the components of loyalty of segment 1 coincided with characteristics of the types of loyalty of class I of the joint classification (Table 1). Thus, the consumers who got to segment 1 , characterised positive manifestations of the following components of loyalty: emotional - the characteristic of a regular customer of this pharmaceutical organisation; behavioural - the buyer purchases pharmaceutical goods from one organisation (considers himself a regular customer), rational - the assessment of the location of the pharmaceutical organisation, price of the goods, and also a possibility of replacement or acquisition of medicine at its absence in other pharmaceutical organisations, etc. This segment contained $26 \%$ of the respondents. Most of them were women (70 \%), over 40 years old, with higher education, and a total family income of US\$240 - 1600 monthly. The average frequency of using pharmaceutical care services is about three times a month. Their annual expenditure on pharmacy products were US\$404 (Table 2).

The respondents in this segment considered themselves to be a group of regular customers and did not identify with factors that would prevent them from making repeated purchases at the pharmacy. We talk about their satisfaction in terms of the primary indicators of the pharmacy; the possibility of switching to competitors' services was considered by us in the view of behavioural tendencies, including the actions of the respondents in the absence of the required drug in the pharmacy.

During the research it was revealed that $46 \%$ of the respondents of this segment, in case of a lack in the availability of the necessary medicine,

Table 2: Consumer segment profiles

\begin{tabular}{|c|c|c|c|c|c|}
\hline \multirow[b]{2}{*}{ Variable } & \multicolumn{4}{|c|}{ Consumers (\%) } & \\
\hline & I (26\%) & II (25\%) & III (39\%) & IV (10\%) & \\
\hline \multicolumn{6}{|l|}{ Gender } \\
\hline Female & 70 & 79 & 62 & 73 & 71 \\
\hline Male & 30 & 21 & 38 & 27 & 29 \\
\hline \multicolumn{6}{|l|}{ Age } \\
\hline$<20$ & 3 & 3 & 11 & 0 & 4 \\
\hline $20-30$ & 16 & 13 & 22 & 23 & 19 \\
\hline $30-40$ & 14 & 24 & 25 & 35 & 25 \\
\hline $40-50$ & 32 & 39 & 23 & 23 & 29 \\
\hline$>50$ & 35 & 21 & 19 & 19 & 24 \\
\hline \multicolumn{6}{|l|}{ Education } \\
\hline Secondary school & 27 & 34 & 31 & 32 & 31 \\
\hline University & 64 & 59 & 48 & 60 & 58 \\
\hline Student & 3 & 2 & 15 & 0 & 5 \\
\hline \multicolumn{6}{|l|}{ Monthly family income } \\
\hline $12000^{*}(\$ 240)$ & 9 & 5 & 3 & 4 & 5 \\
\hline $\begin{array}{l}12000-40000(\$ 240- \\
800)\end{array}$ & 36 & 29 & 31 & 31 & 32 \\
\hline $\begin{array}{l}400000-80000(\$ 800- \\
1600)\end{array}$ & 33 & 50 & 40 & 31 & 39 \\
\hline $\begin{array}{l}80000-120000(\$ 1600- \\
2400)\end{array}$ & 19 & 12 & 21 & 31 & 21 \\
\hline \multicolumn{6}{|c|}{ Average frequency of visits to pharmacies monthly } \\
\hline & 2,99 & 2,66 & 2,13 & 1,45 & 2,3 \\
\hline \multicolumn{6}{|c|}{ Cost of pharmacy products (US\$) } \\
\hline Per month & 33,71 & 30,60 & 30,72 & 41,58 & 34,15 \\
\hline Per year & 404,57 & 367,17 & 368,67 & 498,96 & 409,85 \\
\hline
\end{tabular}

${ }^{\star}$ Minimum living wage (including pensioners and children) at the average rate of US $\$ 1=49.95$ roubles; the average salary in Russia in Moscow in 2014-2015 was US\$689

can wait (three days on average), $10 \%$ agreed to replacements, $32 \%$ agreed to buy the 
medicine from other drugstores, and $12 \%$ of respondents answered that they had never faced a lack of necessary medicine in their particular drugstore.

Above the listed set of criterion allows us to draw a conclusion regarding the existence of the respondents' desires to make repeated purchases (to use the services again) and find a low probability of them switching to the services of competitors. This consumer segment is called "constant consumers".

\section{Segment 2}

The respondents of segment 2, assigned to class III of the joint classification, made up $25 \%$ of the respondents (Table 1). Most were women (79 $\%), 30-50$ years old, with higher education, and a total family income of US\$800 - 1600, used pharmaceutical care services 2.66 times a month, and their annual spending on pharmacy assortment of goods was US\$367 (Table 2).

They are characterised by a positive manifestation of a rational component - the evaluation of the utility of the service. Dissatisfaction with some parameters of the pharmacy's work was revealed, along with (among the reasons that prevented consumers from purchasing goods from one particular pharmacy were; queues improper organisation of work and prices).

These consumers characterise themselves as regular customers with a desire to make repeated purchases from a pharmacy, but in fact do it from different ones. In the absence of the required drug, $26 \%$ of respondents in this segment are ready to wait (two to three days), 20 $\%$ agreed to replacements, and $54 \%$ agreed to get the right drug at another pharmacy. Thus, the probability of switching to the competitors was high. This segment is called "consumers constants imaginary".

\section{Segment 3}

Consumer segment III, regarding a set of components of loyalty and their characteristics, is closest to IVb - evaluative loyalty (Table 1). The main characteristic of this type is a dominant rational component $[3,6]$.

This segment accounted for $39 \%$ of the respondents, $62 \%$ of them women, aged between $20-50$ years old, with secondary/secondary special education, with the total family income being $\$ 240-1600$. They visit the pharmacy about two times a month and their annual spending there was US\$368 (Table 2).

Consumers of segment III, during the research, did not appoint themselves as regular customers, and specified that they make purchases of pharmaceutical goods from various places (negative manifestation of emotional and behavioural components of loyalty). Among the reasons preventing consumers from availing services of one drugstore, the respondents specified a lack of requirement, owing to a large number of drugstores and the similarity of the rendered services (positive manifestation of a rational component).

This set of criteria illustrates the unwillingness to make purchases (including, repeated) from one pharmaceutical organisation, and the constant switching of services to various pharmaceutical organisations.

Only $12.5 \%$ of the respondents were ready to wait for their medicine if not available at the moment, however, only at the impossibility of getting it in other drugstores. This segment is called "incontancy consumers".

\section{Segment 4}

Segment IV was not correlated to any one class of the joint classification, according to the marked-out specifics. Consumers of this segment revealed themselves to be regular customers of the pharmaceutical organisation, but not where they currently made purchases or where our questionnaires were conducted. At the same time, the consumers specified that they made purchases from several drugstores, depending on the circumstances and prioritising them whenever possible; they call themselves regular customers. Thus, the allocation of these consumers in a separate segment, can reveal their behavioural tendencies and their feelings of emotional affection for one pharmaceutical organisation, but purchasing of goods from another. It will also help establish the reasons for switching to the services of competitors.

In segment IV, $10 \%$ of the respondents were women, $63 \%$ was 20 to 50 years old, with higher education, and family income from US $\$ 240$ to 2400. They visited pharmacies no more than once monthly. Their annual expenditure on pharmaceutical goods was $U \$ 519$ (Table 2).

About $26 \%$ of the respondents in this segment were ready to wait for the missing drug, $8 \%$ would agree to a replacement, $15 \%$ acquire the necessary drug at another pharmacy. This consumer segment is called "migrant 
Table 3: Modified classification of loyalty types for the retail segment of the pharmaceutical market

\begin{tabular}{|c|c|c|c|c|c|c|}
\hline \multirow[t]{2}{*}{ Loyalty type } & \multicolumn{6}{|c|}{ Manifestation of loyalty criteria for a given type of loyalty } \\
\hline & Emotional & $\begin{array}{l}\text { Behavioural } \\
\text { (repeat } \\
\text { purchases) }\end{array}$ & $\begin{array}{l}\text { Rational (utility } \\
\text { evaluation) }\end{array}$ & $\begin{array}{l}\text { Consumer } \\
\text { satisfaction }\end{array}$ & $\begin{array}{l}\text { Desire to } \\
\text { acquire } \\
\text { again }\end{array}$ & $\begin{array}{l}\text { Ability to } \\
\text { switch to } \\
\text { competitors }\end{array}$ \\
\hline Constancy & Yes & Yes & Yes & Yes & Yes & No \\
\hline $\begin{array}{l}\text { Constancy } \\
\text { imaginary }\end{array}$ & Yes & No & Yes & Yes & Yes & Yes \\
\hline Inconstancy & No & No & Yes & Yes/No & Yes/No & Yes \\
\hline Migratory loyalty & No & Yes & Yes & Yes & Yes & Yes \\
\hline
\end{tabular}

consumers".

Since the study identified a consumer segment with a type of loyalty previously unreviewed by other authors, a modified classification of the loyalty types for the retail segment of the pharmaceutical market was created to characterise it, as exhibited by the consumers of the pharmaceutical care service. Under this classification, constancy, constancy imaginary, inconstancy, and migratory loyalty are the various types of loyalty (Table 3 ).

Owing to the social orientation of the pharmaceutical business, it should be noted that each allocated consumer segment, in a retail link of the pharmaceutical market, is a target. Simultaneously, segmentation in terms of the loyalty exhibited here, stays relevant as the segment-oriented set of values. Considering this, the feature of inquiries and requirements of its representatives have been developed for each segment.

\section{DISCUSSION}

The analysis of the previously existing loyalty classifications allowed to identify six main behavioral and emotional characteristics of the consumer that influence the formation of the type of loyalty $[1,3,4,6]$. These characteristics have become the criteria used in this study for segmentation of consumers in the retail segment of the pharmaceutical market. In the result of the study, there were 4 formed segments; three of them were previously described by other authors (segment 1 - constancy, 2 segment - constancy imaginary, 3 - inconstancy). The fourth segment differs in a set of consumer characteristics from earlier known types. A new type of loyalty has been identified by our study - "migratory loyalty".

Based on the obtained data for Russian customers, a new classification of loyalty types adapted to the specifics of the pharmaceutical market has been created. This classification can serve as a basis for customer loyalty segmentation, since it contributes to the selection of a segment with clearly readable tendencies to repeated purchases in community pharmacy, resistance to competitors' actions, gives more opportunities to assess missed profits. The concentration of marketing efforts on a particular consumer segment will reduce the cost of attracting and retaining customers.

\section{Limitations of the study}

The present study was conducted in various territorial districts and pharmacies of several forms of ownership. However, due to the large number of pharmacies in Moscow (more than 3,000 ), each of which serves more than 200 customers daily, the study was limited since it did not the entire pharmacy consumer population.

\section{CONCLUSION}

The current study identified four customer loyalty types in a retail segment of the Russian pharmaceutical market. Additionally, a modified loyalty type was also created to fit the pharmaceutical market status. There is high competition amongst the retail drugstore chains in Russia. Therefore, the use of marketing, behavioural, and psychological approaches for assessing the quality of pharmaceutical care rendered is required. This will assist in enhancing the competitive capability of pharmacies. One such approach could define the priority consumer segments, based on their loyalty in terms of the place of shopping. Furthermore, the main consumer tendencies and the optimisation of pharmaceutical care practice for each segment would be clearer. 


\section{DECLARATIONS}

\section{Acknowledgement}

The authors are grateful to members of the Department of Pharmaceutical Management and Economics of the Peoples' Friendship University of Russia, and to the pharmacy organisations who assisted in conducting this study.

\section{Conflict of interest}

No conflict of interest is associated with this work.

\section{Contribution of authors}

We declare that this work was conducted by the authors named in this article and all liabilities pertaining to the claims in the content of this article will be borne by the authors. The originator of the idea, the developer of the research design, and general control of the research was carried out by Galina Galkina. All the listed authors were participants in the research group and were engaged in collecting and processing data. All the authors read and approved the manuscript for publication.

\section{Open Access}

This is an Open Access article that uses a funding model which does not charge readers or their institutions for access and distributed under the terms of the Creative Commons Attribution License (http://creativecommons.org/licenses/by/ 4.0) and the Budapest Open Access Initiative (http://www.budapestopenaccessinitiative.org/rea d), which permit unrestricted use, distribution, and reproduction in any medium, provided the original work is properly credited.

\section{REFERENCES}

1. Tsysar AV. Customer loyalty: Basic definitions, measurement methods, management methods. Mark Mark Res 2002; 5: 55-61.

2. Shirochenskaya IP. The basic concepts and methods of measurement of loyalty. J Mark Rus Abroad 2004; 2: 22-24.

3. Aaker DA. Creation of strong brands. Moscow: Publishing House of Grebennikov; 2003.

4. Sheth J, Park C. A theory of multidimensional brand loyalty. Adv Consum Res 1974; 3: 449-459.

5. Reicheld F, Markey R. Sincere loyalty. The key to winning customers for life. The ultimate question 2.0: How to promoter companies. Moscow: Mann, Ivanov and Ferber; 2013.

6. Hofmeyr J, Rice B. Commitment Led Marketing. New York: John Wiley and Sons; 2000.

7. McKenna R. Relationship marketing: Successful strategies for the age of the customer. Boston: AddisonWesley Publishing Company; 1993.

8. Galkovskaya G. Global pharmacy market: Part 1 Infrastructure and key features, 2015 [cited 2015 Oct 26]. Available from: https://www.apteka.ua/article/349023.

9. Government of the Russian Federation. Resolution № 1081 "On licensing of pharmaceutical activities" by Dec 22, $2011 ; 2011$.

10. World Medical Association. World Medical Association Declaration of Helsinki: ethical principles for medical research involving human subjects. JAMA 2013; 310: 2191-2194. 